\title{
Um aplicativo para estudo de insolação em projetos arquitetônicos
}

\author{
Gabriel Brazão de Almeida', Olavo Nylander Brito Neto ${ }^{1}$ \\ 'Instituto Federal de Educação, Ciência e Tecnologia do Amapá (IFAP) - Campus \\ Macapá \\ Rod. BR-210, Km 03, S/n - Brasil Novo, Macapá, Amapá - Brasil \\ gabriel-brazao@hotmail.com, olavo.brito@ifap.edu.br

\begin{abstract}
Resumo. Este artigo apresenta o InsolarQ, um aplicativo que visa auxiliar as disciplinas introdutórias de conforto ambiental e projeto arquitetônico dos cursos de nível superior em arquitetura e urbanismo. $O$ aplicativo possui ferramentas para simulação de insolação nos ambientes internos e externos de uma maquete eletrônica, tais como controle de movimento do Sol, e visualização. $O$ aplicativo tem como objetivo fornecer ferramentas intuitivas para introduzir conceitos sobre conforto térmico em uma análise qualitativa de projetos, desta forma possibilitando o uso da tecnologia no processo de ensino e aprendizagem dos cursos de arquitetura e urbanismo.
\end{abstract}

\section{Cenário de uso}

O estudo de projetos arquitetônicos e urbanísticos nos cursos de arquitetura e urbanismo encontram-se (ou deveriam encontrar-se) em constante transformação devido ao avanço da tecnologia, especialmente as relacionadas a visualização de espaços virtuais tridimensionais. A tecnologia é um elemento essencial no processo de projeto, pois constitui-se de ferramenta de pré-visualização do estudo, o que direciona o projeto a alterações que levam ao resultado desejado.

Eliseo, et al. (2014) destaca que os ambientes virtuais tridimensionais são uma forma de motivação ao aprendizado que leva a maior envolvimento e melhor entendimento do espaço tridimensional. Atualmente, é possível obter diversas ferramentas que auxiliam na elaboração e visualização de projetos, como SketchUp e Revit. Ambos possuem ferramentas para modelagem de edifícios e espaços urbanos, bem como de simulação da insolação e sombreamento, o que os caracteriza como excelentes ferramentas para os estudantes.

Com o surgimento de ferramentas como o motor de jogos Unity3D, desenvolvido pela empresa Unity Technologies, a arquitetura e o urbanismo passam a investigar novas possibilidades de utilização de ambientes tridimensionais para visualização de projetos e simulação de seus elementos condicionantes. Indraprastha e Shinozaki (2009) e Buyuksalih et al. (2017) realizaram estudos de visualização de espaços urbanos e simulação da insolação em edifícios utilizando o Unity3D, e apontaram vantagens de sua utilização para este fim, dentre as quais destacam-se as ferramentas de visualização e renderização da luz em objetos tridimensionais, e a possibilidade de desenvolver um aplicativo capaz de agregar ferramentas de visualização e simulação ao mesmo tempo. 
VIII Congresso Brasileiro de Informática na Educação (CBIE 2019)

Anais dos Workshops do VIII Congresso Brasileiro de Informática na Educação (WCBIE 2019)

Como desvantagens, os autores apontam limitações gráficas comparadas a outros motores de jogos como o Unreal Engine, além de não possuir ferramentas nativas de modelagem de elementos de arquitetura e urbanismo.

Desta forma, depreende-se que a visualização e simulação é essencial para o estudo na arquitetura e no urbanismo, e sua importância pode ser enfatizada em diversos estudos, dentre os quais, pode-se citar Silva et al. (2016).

Este artigo apresenta o InsolarQ, um aplicativo para dispositivos móveis que objetiva realizar simulação de insolação e sombreamento em ambientes para arquitetura e urbanismo. É direcionado a estudantes do ensino superior dos cursos de arquitetura e urbanismo, especificamente para as disciplinas introdutórias de conforto ambiental e projetos arquitetônicos.

\section{Desenvolvimento}

Este aplicativo foi desenvolvido no motor de jogos Unity3D, versão 2018.3.9f1, um software multiplataforma voltado principalmente para a indústria de jogos, além de diversos outros produtos para indústria do cinema, da construção civil, dentro outras. Além disso, o Unity3D utiliza a linguagem de programação C\# em seu ambiente de desenvolvimento.

O aplicativo foi desenvolvido como parte da avaliação da disciplina de Desenvolvimento de Aplicativos Móveis, da Pós-Graduação em Informática na Educação do Instituto Federal do Amapá, e o processo de desenvolvimento teve início com um brainstorming, no qual cada aluno apresentou um esboço para seu aplicativo, onde o mesmo foi submetido a sugestões do professor e de alunos.

Foi então projetado utilizando wireframes, no qual se esboçou com papel e lápis a estrutura básica e design das telas do aplicativo. Na sequência, iniciou-se a sua construção no Unity3D, no qual o projeto sofreu pequenas alterações. Em uma etapa final, o aplicativo foi apresentado e testado pelos alunos e professor, em que foram sugeridas alterações/inclusões/exclusões de funções que foram filtradas e aplicadas para esta versão do protótipo.

Para a modelagem dos objetos tridimensionais necessários à simulação, foi utilizado o software Blender, versão 2.79. Caracteriza-se por ser gratuito, largamente utilizado em diversos setores devido à facilidade de aprendizagem, e diversas possibilidades de exportação do objeto modelado para outros softwares. Os objetos, então, foram modelados e exportados para o Unity3D.

\section{Apresentação do Software}

O Unity3D permite desenvolver o aplicativo para diversas plataformas. No entanto, foi principalmente pensado para dispositivos móveis. Sendo assim, o aplicativo foi disponibilizado para Android, e pode ser baixado no endereço eletrônico https://drive.google.com/open?id=1OxMVUPog9LOZmgJ8pB_MZ2gLuwtXaNM3, e o vídeo demonstrativo visualizado em https://youtu.be/TvbpK7eT7Uk.

O aplicativo possui a tela inicial, no qual o usuário seleciona um ambiente previamente modelado, e a tela de simulação, onde ocorre a manipulação de diversas 
VIII Congresso Brasileiro de Informática na Educação (CBIE 2019)

Anais dos Workshops do VIII Congresso Brasileiro de Informática na Educação (WCBIE 2019)

ferramentas como visualizações internas e externas do modelo, bem como configurações de sua localização e controle da posição do sol.

\subsection{Tela inicial}

Na tela inicial o usuário encontra opções de ambientes previamente modelados e um botão para fechar o aplicativo. É necessário optar por algum dos modelos disponíveis para prosseguir para a tela de simulação.

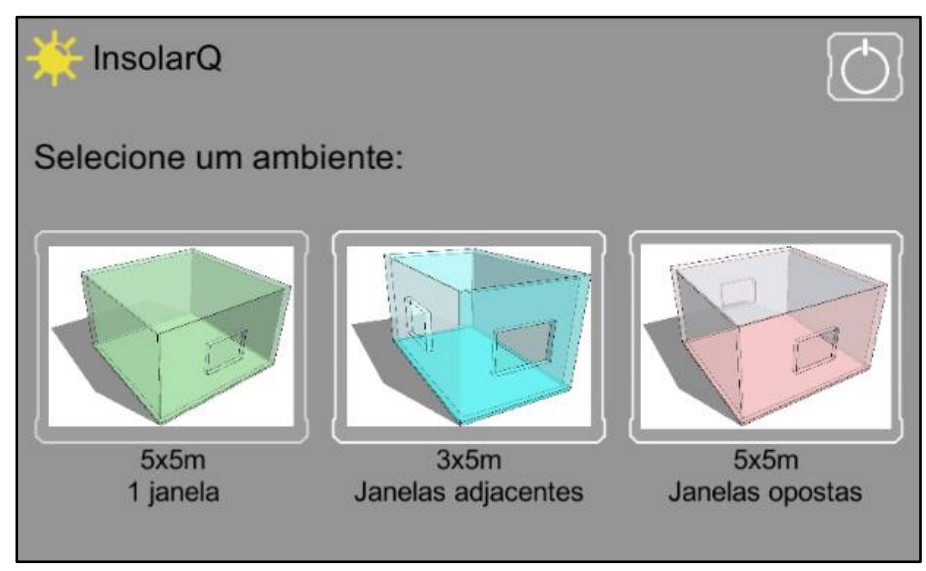

Figura 1 - Tela inicial.

Os ambientes foram modelados tendo em vista trazer resultados relevantes para o estudo de sombreamento das edificações no entorno, bem como manchas solares internas ao ambiente. Desta forma, este protótipo possui três modelos detalhados a seguir:

a. Modelo com uma abertura: o ambiente possui dimensões de $5,00 \times 5,00 \mathrm{~m}$, paredes com $0,15 \mathrm{~m}$ de espessura, pé-direito de $3,00 \mathrm{~m}$ e um piso elevado $0,10 \mathrm{~m}$ do nível do solo. Há também uma abertura posicionada na fachada oeste, cuja suas dimensões são de 1,50x1,10m e 1,10m de peitoril.

b. Modelo com duas aberturas em paredes adjacentes: neste ambiente de dimensões $3,00 \times 5,00 \mathrm{~m}$, paredes com $0,15 \mathrm{~m}$ de espessura, pé-direito de $3,00 \mathrm{~m}$ e um piso elevado $0,10 \mathrm{~m}$ do nível do solo, há uma janela posicionada nas fachadas norte e leste, desta forma evidenciando diferentes situações de manchas solares no mesmo ambiente interno. As aberturas possuem as mesmas dimensões do modelo anterior.

c. Modelo com duas aberturas em paredes opostas: outro ambiente de dimensões $5,00 \times 5,00 \mathrm{~m}$, paredes com $0,15 \mathrm{~m}$ de espessura, pé-direito de $3,00 \mathrm{~m}$ e um piso elevado $0,10 \mathrm{~m}$ do nível do solo, em que as aberturas estão posicionadas nas fachadas oeste e leste. A dimensão das aberturas são as mesmas dos modelos anteriores. 


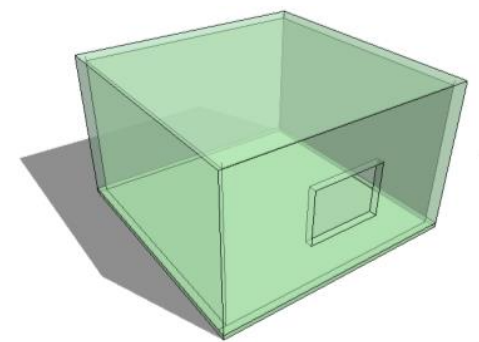

(a)

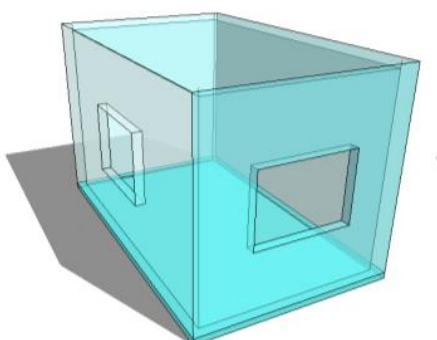

(b)

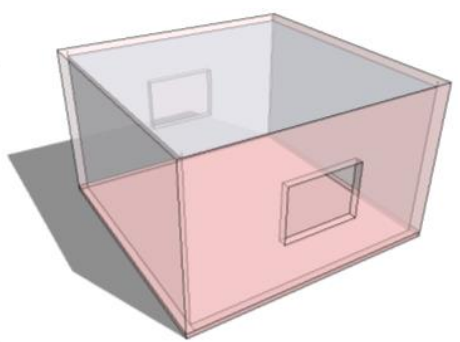

(c)

Figura 2 - (a) Modelo com uma abertura. (b) Modelo com duas aberturas adjacentes. (c) Modelo com duas abertura opostas.

\subsection{Tela de simulação}

Na tela de simulação o modelo selecionado anteriormente é visualizado na área principal. Um menu localizado no canto superior esquerdo da tela, ao ser pressionado, expande-se, exibindo as ferramentas de manipulação do modelo, além de um botão para voltar à tela inicial.

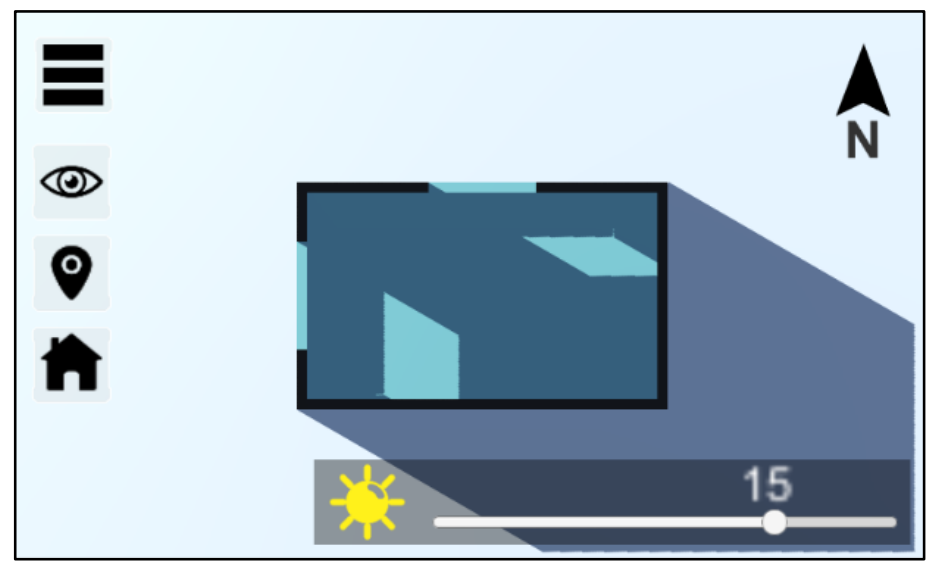

Figura 3 - Tela de simulação.

As ferramentas disponíveis no aplicativo são explicadas a seguir:

a. Movimento do Sol: o usuário alterna entre as horas do dia no controle deslizante localizado no canto inferior direito da tela, alterando assim a posição do Sol na abóbada celeste. No menu de localização, para este protótipo está disponível apenas a latitude $0^{\circ}$, referente a locais que se encontram na linha do Equador, com opções de simulação nos solstícios e equinócio, conforme figura 4. 
VIII Congresso Brasileiro de Informática na Educação (CBIE 2019)

Anais dos Workshops do VIII Congresso Brasileiro de Informática na Educação (WCBIE 2019)

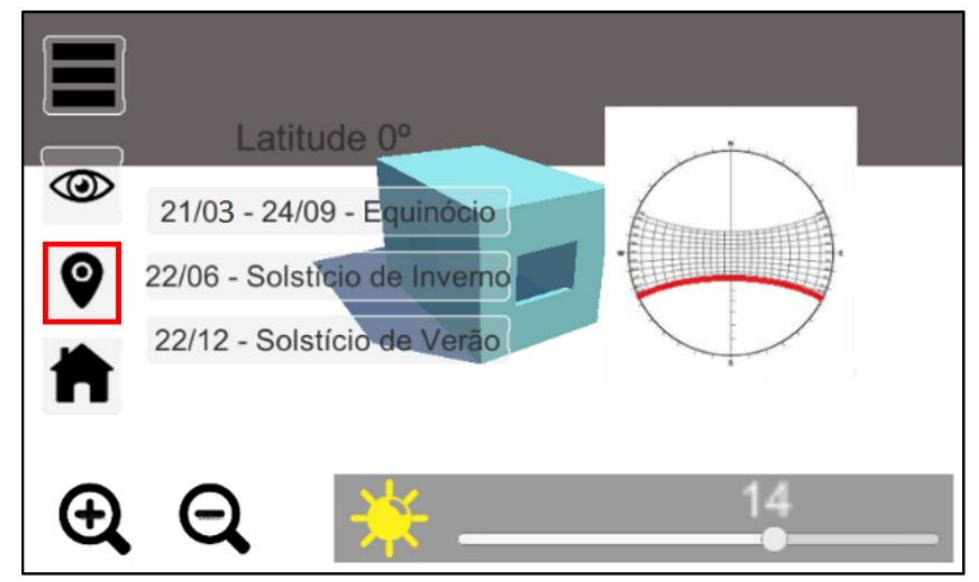

Figura 4 - Menu para escolha do dia de simulação.

b. Visualização: o usuário pode alternar as vistas do ambiente em norte, sul, leste e oeste, bem como uma vista tridimensional, superior, e planta baixa. Há também no canto inferior esquerdo opções simplificadas de zoom para a vista tridimensional, conforme figura 5 .

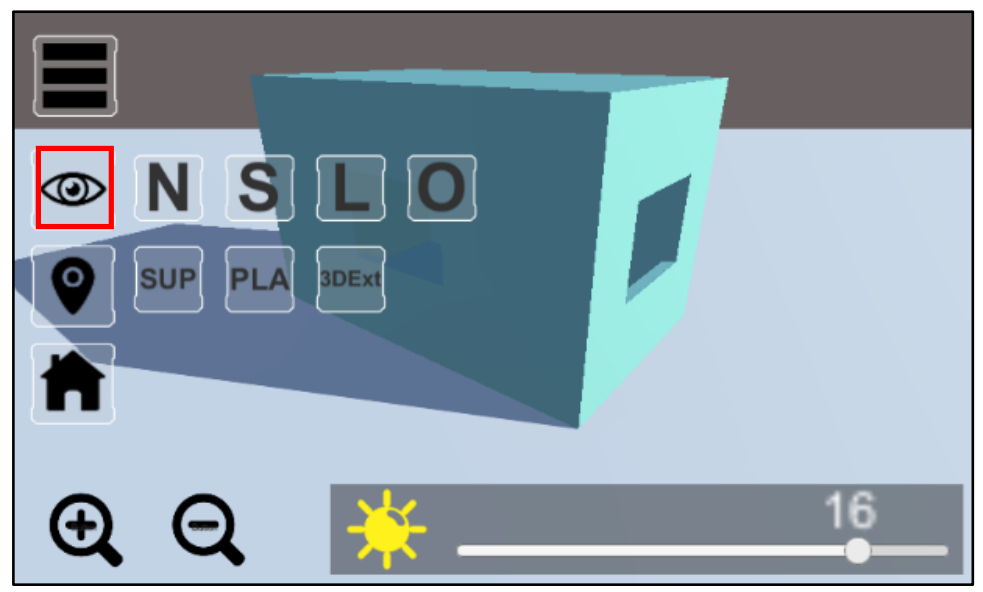

Figura 5 - Ferramentas de visualização.

\section{Considerações finais}

O uso deste aplicativo pode facilitar o entendimento do conteúdo introdutório das disciplinas de conforto ambiental, principalmente nos estudos de conforto térmico, através do uso da tecnologia. Pode ser usado para exercícios de análise qualitativa dos ambientes de um projeto e auxiliar na elaboração do mesmo.

Vale ressaltar que, por se tratar de um aplicativo em desenvolvimento, ainda há ferramentas e funções a serem incluídas, bem como realizar melhorias em sua interface, tornando-o mais intuitivo. As atualizações e melhorias futuras para este aplicativos são explicadas a seguir:

a. Localização por mapa: esta ferramenta terá por objetivo exibir um mapa, no qual o usuário seleciona um local, e o aplicativo captura a latitude e 
VIII Congresso Brasileiro de Informática na Educação (CBIE 2019)

Anais dos Workshops do VIII Congresso Brasileiro de Informática na Educação (WCBIE 2019)

longitude do mesmo. Desta forma, o aplicativo gera o movimento aparente do Sol correspondente àquela latitude;

b. Modelagem básica e importação: além de poder escolher um ambiente previamente modelado, o aplicativo irá permitir modelar ambientes básicos com a inclusão de ferramentas de modelagem como paredes, aberturas e seus dispositivos de proteção, cobertura e piso, bem como importar para o aplicativo modelo tridimensional;

c. Análise e gerenciamento de informações quantitativas: pretende-se implantar em próximas atualizações geração de cartas solares, máscaras de sombra, medidas do sombreamento no entorno, área da mancha solar projetada no ambiente interno, dentre outros dados quantitativos. Além disso, o aplicativo deverá salvar as imagens e dados quantitativos gerados na simulação, permitindo exportá-los.

\section{Referências}

Buyuksalih, I., Bayburt, S., Buyuksalih, G., Baskaraca, A.P., Karim, H. and Rahman, A.A. (2017) 3D Modelling and Visualization Based on the Unity Game Engine Advantages and Challenges. In ISPRS Annals of the Photogrammetry, Remote Sensing and Spatial Information Sciences (Vol.4, No.4, p.161-166).

Eliseo, M.A., Delmondes, D.S.A., Falavigna L.H. and Garcia, J.H. (2014) Uma Discussão sobre Ambientes Virtuais 3D como Suporte ao Estudo de Arquitetura. In Anais do Workshop do Congresso Brasileiro de Informática na Educação (Vol.3, No.1, p.505514).

Indraprastha, A. and Shinozaki M. (2009) The Investigation on Using Unity3D Game Engine in Urban Design Study. In ITB Journal of Information and Communication Technology (Vol.3, No.1, p.1-18).

Silva, I.C.S., Morais, A.S. and Almeida, G.B. (2016) "A influência da morfologia urbana sobre a temperatura do ar na região amazônica", In Estudos Urbanos e Regionais no Trópico Úmido: Pensando a Cidade Amazônica na Contemporaneidade, Costa, J.M. (org.), Autografia; UNIFAP, p.201-212. 